\title{
AN UNCOMMON SEVERE CLINICAL COURSE OF EUROPEAN TICK-BORNE ENCEPHALITIS
}

\author{
Roman Herzigi, , Carl Matthias Patt ${ }^{\mathrm{a}}$, Tamara Prokes ${ }^{\mathrm{a}}$ \\ a Department of Neurology, Christian Doppler Clinic, Salzburg, Austria \\ ${ }^{b}$ Clinic of Neurology, Faculty Hospital, Olomouc, I. P. Pavlova 6, CZ-775 20 Olomouc, Czech Republic \\ e-mail:herzig.roman@seznam.cz
}

Received: September 21, 2002

Key words: Tick-borne encephalitis / Meningoencephalomyelitis / Clinical course / Mortality

Tick-borne encephalitis (TBE) is the major European arbovirosis. Man is often infected by the tick bite; laboratory infections as well as infections after consumption of nonpasteurized milk have occasionally been reported. TBE typically takes a biphasic course. After an incubation period (7-14 days usually), the prodromal symptoms occur. The first stage of the disease lasts 1-8 days. After an afebrile asymptomatic interval of approximately 1-week the second stage develops, in which TBE may manifest as isolated meningitis, meningoencephalitis, meningoencephalomyelitis and/or radiculitis. The mortality rate is $0-3.3 \%$. There is high frequency of sequelae. Patients who have suffered from a TBE infection are immune for the rest of their lives. At present there is no effective antiviral therapy and management is strictly supportive. Active immunization against TBE is recommended for all subjects living in and travelling to areas of risk. Passive immunization is recommended only within 48 hours after a tick bite. The authors present the case report of 75-years old female subject, who suffered from the uncommon severe clinical course of TBE - with the development of consciousness impairment, tetraplegia, and dyspnoea (demanding ventilatory support). Her state was complicated by the transient left side faciobrachial motor Jackson's convulsions, blood pressure instability, heart arrhythmia, respiratory infection, anemia, and by the development of critical illness neuropathy. Although she made slow progress during treatment, she died on the $114^{\text {th }}$ day because of suspected aspiration.

\section{INTRODUCTION}

Tick-borne encephalitis (TBE) is a major European arbovirosis $^{1}$. It has occurred regularly in Europe since it was first diagnosed in 1931 by Schneider ${ }^{2}$. It is endemic in certain areas of Central and Eastern Europe, such as Austria, the Czech Republic, the south of Germany ${ }^{3-6}$, Hungary, Poland ${ }^{7}$, Russia ${ }^{1}$, Slovakia, the former Yugoslavia $^{2,8,9}$, but also in Denmark ${ }^{10}$ and in certain areas of France (Alsace) ${ }^{1}$, Sweden ${ }^{11-13}$ and Finland. ${ }^{14}$

TBE is caused by a RNA virus belonging to the flavivirus family; the virus is transmitted by larval, nymphal and adult ticks to human beings ${ }^{1,3,10,14}$. Tick is also a virus reservoir; it remains infected throughout its life, through its metamorphosis and transmits the virus to its progeny. Vector-ticks belong to various species of a same genus; Ixodes persulcatus in Far-Eastern Russia, Ixodes ricinus in other European foci. Small rodents (field mouse, vole) are the main vertebrate hosts. Extension and creation of new natural foci are caused by big mammalians and by migratory birds which carry over the virus and vector ticks. ${ }^{1}$ Epidemiological studies have shown that in endemic areas $0.1 \%$ of the ticks harbor the virus. Man is often infected by the tick bite; laboratory infections ${ }^{15-17}$ with the TBE virus as well as infections after consumption of nonpasteurized milk have occasionally been reported ${ }^{7}$. Person-to-person transmission has not yet been observed, but it may be theoretically conceivable if blood from a patient who is in the stage of viremia is inoculated into another person. ${ }^{10}$

The antibody prevalence among the European population is between $0.5 \%$ and $1.5 \%$. Among patients living in the endemic areas this shows a considerable variation, e.g., 4-8\% (Germany), 14\% (Austria), and 30$40 \%$ (territory of the former Czechoslovakia). Risk groups for the infection are forest workers, hikers, strollers, and collectors of mushrooms and berries, with seroprevalences of 4-16\% (Switzerland), 4-22\% (Sweden $)^{18}, 11-50 \%$ (former Czechoslovakia), 30\% (Denmark), and $41 \%$ (Austria). The risk of being infected with TBE virus after a tick bite in an endemic area in Germany is estimated at 1:900. ${ }^{10}$ 


\section{CASE REPORT}

A 75-years old female Caucasian was previously healthy. She was married and lived with her husband. During the Easter 2000 (April 22-24) she spent her holiday near Vienna. She walked through the forests several times. She did not notice any tick bites.

On May 6 (Day 1, approximately two weeks after the holiday) she suffered from abdominal pain. A weakness in both legs appeared on the same day in the evening. She fell in the night when getting out of the bed. She was admitted to the Department of Traumatology in Salzburg on the $2^{\text {nd }}$ day. Subcutaneous haematoma was present on the forehead; no traumatological pathological changes were found in the X-ray of the skull. She was transferred to the Department of Geriatrics, Christian Doppler Clinic, Salzburg. The clinical state worsened during the $4^{\text {th }}$ day - tetraparesis and dyspnoea developed. She was transferred to the Intensive Care Unit (ICU) in the Department of Neurology, Christian Doppler Clinic on the same day. Besides other laboratory tests, lumbar puncture (LP) was performed; the cell count was $31 \times 10^{6} / 1$ (mononuclears and activated lymphocytes were present), total protein level was $0.99 \mathrm{~g} / \mathrm{l}$ in the cerebrospinal fluid (CSF).

At the time of admission to the ICU she was conscious and oriented, her mood was dysphoric and her speech was dysarthric. She had bilateral rotatory nystagmus in conjugated eye movements to both sides, discrete right side facial nerve paresis, and high-grade peripheral type tetraparesis were present; the deep tendon reflexes were absent and the gag reflex response was reduced. Other neurological findings were normal (neither signs of meningeal irritation, nor pyramidal spastic signs were present). She was dyspnoeic, but other internal findings were normal.

The findings in the magnetic resonance imaging (MRI) of cervical spine and spinal cord were normal, computed tomography (CT) of the brain showed multiple postischaemic changes and atrophy of the brain on the day of admission to ICU. Due to her worsening dyspnoea the patient was intubated and assisted ventilation started. During the next days the ventilatory regime was adapted to the patient's current state. The F-waves were absent in the upper extremities, but were present in lower extremities in the electromyography (EMG) performed on the $5^{\text {th }}$ day. On the $6^{\text {th }}$ day the patient was opening her eyes upon tactile stimulation, eyeballs were deviated upwards, the gag reflex response was still low. On the $7^{\text {th }}$ day left side faciobrachial motor Jackson's convulsions appeared in the morning, lasting for 2 minutes (diazepam was administrated intravenously); electroencephalography (EEG) showed middle grade non-specific changes and the presence of an epileptic active focus in the right hemisphere; CT of the brain revealed no contrast enhancement. The information about the positive CSF and serum TBE-specific IgM antibodies (the samples were taken on the $4^{\text {th }}$ day) was obtained on the $7^{\text {th }}$ day. On the $20^{\text {th }}$ day the patient did not exhibit spontaneous blinking; oculo-cephalic reflexes were positive, the muscles in the extremities were atonic, and no pyramidal spastic signs were present. MRI (performed on the $21^{\text {st }}$ day) showed the supratentorial multiinfarcted postischaemic changes, minimal ischaemia in the right pons, and the brain atrophy; there was no pathological contrast enhancement present. EMG (performed on the $35^{\text {th }}$ day) revealed critical illness neuropathy with damage to axon and myelin.

The patient underwent several lumbar punctures. The CSF cell count reached its maximum on the $7^{\text {th }}$ day (the value of $51 \times 10^{6} / 1$; monocytes, activated lymphocytes and few granulocytes were present), but the value decreased to $20-26 \times 10^{6} / 1$ between the Days 12 and 18 , and became normal from the $21^{\text {st }}$ day. The total protein level reached its maximum $(1.79 \mathrm{~g} / \mathrm{l})$ on the $12^{\text {th }}$ day; it decreased in the other LPs down to $0.46 \mathrm{~g} / 1$ (on the Day 25).

EEG was also controlled several times. The one performed on the $10^{\text {th }}$ day showed middle grade nonspecific changes, no focus was present. Two days later the EEG revealed the presence of epileptic activity in the right fronto-temporal region, beside the middle grade non-specific changes. On the $20^{\text {th }}$ day EEG showed the diffusely increased paroxysmal readiness. There were no seizures in the patient during this time.

The course of the illness was complicated by the respiratory infection (the X-ray of the chest was repeated several times and showed, that there was fluctuating picture of bilateral bronchitis and of left side basal pneumonia since the $6^{\text {th }}$ day - therefore, a tracheostomy was performed on the $15^{\text {th }}$ day); blood pressure instability (both with arterial hypotension, and hypertension); heart arrhythmia (the episodic supraventricular tachycardia occurred several times since the $27^{\text {th }}$ day); and anemia (two doses of erythrocyte concentrate transfusion were administered on the $15^{\text {th }}$ and on the $34^{\text {th }}$ day).

On the $53^{\text {rd }}$ day the patient was still soporous, ventilated, with subtotal tetraplegia - only minimal tonus in tibial muscle, and the minimal movement of the head and of the right shoulder were present inconstantly during the last weeks.

However, on the $67^{\text {th }}$ day she started to move her head towards both sides, and also had movement in her right toe. One day later little movement of her right shoulder was present. On the $70^{\text {th }}$ day she was able to breathe without the help of the ventilator (and ever since then she has been able to do so); on the same day she did understand - for the first time since more than two months - simple commands which she responded to by nodding, and wiggling her head. She was transferred from ICU to intermediary care unit on the $64^{\text {th }}$ day. Since then she made slow but definite progress continuously. Three months after the onset of symptoms she was still bedridden, she did understand spoken language and responded adequately to simple commands. She was mobilized by physiotherapists to upright position in bed (self control of her head position was possible), she was breathing via tracheostomy; her motor 
function was still limited to little voluntary movements of both hands and feet.

The patient was discharged from the hospital to the nursery home on the $103^{\text {rd }}$ day. She was readmitted to the hospital because of a febrile urinary tract infection 6 days later; she was discharged again on the next day. However, according to the information from her family doctor, the patient died on the $114^{\text {th }}$ day because of suspected aspiration - she was found dead in her bed in the night by the nurse on the ward round; an autopsy was not performed.

\section{DISCUSSION}

TBE typically takes a biphasic course (in approximately $75 \%$ of the cases) $)^{2}$. After incubation period, lasting 2-28 days, but with the period of 7-14 days most often observed, the prodromal symptoms (uncharacteristic influenza-like illness with fever, headache, malaise, myalgia, and fatigue) occur. This first stage of the disease lasts 1-8 days and correlates with the stage of viremia. After an afebrile interval (patients are free of symptoms during this period) of approximately 1 week (with the range of 1-33 days) the second stage develops. In this second stage TBE may manifest as isolated meningitis, meningoencephalitis, meningoencephalomyelitis and/or radiculitis 3 , 10, 11, 19-23.

Approximately two thirds of persons infected with TBE virus have an inapparent infection with viremia, or have only the first stage of the disease with nonspecific symptoms. Progression to the second stage of the disease is observed in approximately one third of infected persons; about $50-77 \%$ of these patients have the typical biphasic course of the disease. In the remaining 23$50 \%$ the first stage of the disease is inapparent and the clinical disease begins directly with the second stage. ${ }^{10}$

Abdominal pain (as the first prodromal symptom) occurred after approximately 2 weeks lasting incubation period in our patient. However, the further clinical course was uncommonly severe and quick; the first neurological symptom occurred on the same day as the prodromal one. Typical biphasic course was not observed in this case. Furthermore, the worsening of the clinical state was very rapid - with the development of tetraparesis and dyspnoea three days later.

The diagnosis of TBE is derived from epidemiological (a stay in an area of risk for TBE, facultative history of tick bite), and clinical (the above mentioned biphasic course of disease and neurological symptoms with ataxia, followed by paresis or paralysis, being most indicative for this infection) data, and the demonstration of TBEspecific IgM and IgG antibodies in serum by enzymelinked immunoassay. In nearly all patients with TBE serum IgM and IgG antibodies can be detected at the time of hospital admission. Although intrathecal synthesis of TBE-specific IgM and/or IgG antibodies in cerebrospinal fluid is the most specific serological method of confirming the diagnosis, the presence of spe- cific $\operatorname{IgM}$ antibodies in serum is generally considered to be adequate evidence of recent TBE. The CSF reveals a lymphocytic pleocytosis up to 1,600 cells $\times 10^{6} / 1$. The total protein content is elevated and reaches $0.5-2 \mathrm{~g} / 1.3,4$, 10, 19, 21 The TBE-specific IgM antibodies were found in both the serum, and the CSF in our patient (the samples were taken approximately 18 days after the infection). The CSF cell count reached its maximums of 51 cells $\times 10^{6} / \mathrm{l}$, and CSF total protein reached its maximums of $1.79 \mathrm{~g} / \mathrm{l}$ in our case.

The clinical course of the disease can be predicted upon the results of selected clinical and laboratory parameters. The most striking signs of an unfavourable course are the rapid development of unconsciousness (Glasgow Coma Scale $<7$ ) as well as paresis of the limbs and lower cranial nerves. Both the quick consciousness impairment, and the limb pareses development were present in our patient. Of the laboratory parameters, only the finding in magnetic resonance imaging (MRI), cell count and total protein in the CSF correlate with the global outcome of disease. ${ }^{3}$ In our patient the CSF cell count was relatively low; however, the total protein level was significantly elevated. MRI findings were abnormal in $17 \%$ of patients with meningoencephalitis, and in $28 \%$ of patients with meningoencephalomyelitis in the study performed by Kaiser ${ }^{3}$. In our patient, the findings in the MRI of cervical spine and spinal cord were normal on the day of admission to ICU. MRI performed on the $21^{\text {st }}$ day, it showed only postischaemic changes (both supra- and infratentorial) and the brain atrophy. It means no changes typical for TBE were found, in despite of the severe course of the illness.

Prognosis of the disease is also under geographical variations: severe in Far-Eastern Russia and much milder in Central Europe ${ }^{1}$. Nevertheless, our patient developed the severe clinical course of the disease in Austria.

The mortality rate of patients with this disease is $0-3.3 \%{ }^{2-4,8,10,11,20}$. Death usually occurs in the acute stage of illness due to different causes: in severe encephalitis the mortality is due to hypoxic-ischaemic brain damage and brain oedema with tonsilar herniation; the damage to vital centers in the brainstem affections, as well as patients' (in severe course of the disease, treated in the ICU) exposure to nosocomial infections, and other complications due to artificial ventilation can be another cause of death. ${ }^{2,15,23}$ Tomazic et al. ${ }^{2}$ have described the case report of 28 -year-old patient, who died shortly after the onset of the TBE. In general, adolescents (mainly in the age group up to 14 years) have a more favourable course of the disease than adults ${ }^{3,10,12,22}$. However, Messner has reported the fatal case of TBE in adolescents; failure to recognize abdominal symptoms as criteria of the prodromal stage of TBE occurred in this case ${ }^{25}$. Abdominal pain has developed as the first symptom in our case, too. Up to the $40^{\text {th }}$ year of age meningitic courses are usually observed. With increasing age, especially in patients over 60 years, severe clinical courses with paralytic symptoms may develop. ${ }^{10} \mathrm{On}$ 
the contrary Günther et al. have not found the severity of the clinical course increasing with age in their study ${ }^{11}$. Our patient, who died on the $114^{\text {th }}$ day because of suspected aspiration, was aged 75 .

There is high frequency of sequelae (mainly cognitive central nervous system dysfunction) in patients with TBE. In the previous (both retrospective, and prospective) studies the frequency of all sequelae at the discharge from the hospital ranged from 7 to $40 \%$, and the frequency of residual pareses at the discharge from the hospital ranged from 0.3 to $10 \%$, 3, 6, 7, 9, 10, 12, 13, 19-21, 26 . Günther et al. have found encephalitic symptoms in $40 \%$, and spinal nerve paralysis symptoms in $56 \%$ of TBE patients still present after 1 year of clinical course ${ }^{11}$.

Patients who have suffered from a TBE infection are immune for the rest of their lives and their sera show a detectable IgG antibody titer against $\mathrm{TBE}^{10}$.

At present there is no effective antiviral therapy and management is strictly supportive ${ }^{10}$. In view of the severity of the illness and the high frequency of sequelae, active immunization against TBE is recommended for all subjects living in and travelling to areas of risk ${ }^{3,10,14}$. The primary series consists of three doses of vaccine containing purified, formalin-inactivated TBE virus. The recommended date for the first dose is during winter months, followed by the second within 1-3 months and the third dose 9-12 months later. The duration of the protection after the basic immunization is at least 3 years. The protection rate after two doses is $95 \%$ and after three or more vaccinations $99 \%{ }^{10}$. However, neurological complications such as postvaccinal neuritides, but also substantial neurological side effects can occur in a small number of vaccinees $(<1: 100,000)^{10,27}$. The vaccination could protect our patient from the severe neurological impairment with the high probability.

Prevention of TBE by post-exposure prophylaxis with hyperimmunoglobulins (usually to the 48 hours limit after a tick bite at maximum - with a dosage of $0.2 \mathrm{ml}$ of hyperimmunoglobulin per $\mathrm{kg}$ of body weight) is less effective and therefore should be performed only when absolutely necessary ${ }^{3}$. However, some authors ${ }^{10}$ suggest passive immunization with $\mathrm{IgG}$ antibodies against TBE virus up to the $4^{\text {th }}$ day after a tick bite in nonimmunized persons in an area endemic for TBE. The protective efficacy of TBE-IgG is approximately $75 \%$. If the bite is 4 or more days old a prophylactic effect of $\mathrm{IgG}$ is not to be expected. On the contrary, it may even have a negative effect on the course of the disease. ${ }^{3,10}$ Our patient was admitted to the hospital approximately 2 weeks after the infection.

Avoiding ticks bites by wearing tight clothes and using repellents is another method of prophylaxis for people going to or living in registered TBE natural foci ${ }^{1}$.

We think, that the severe development of the illness in our patient was less common due to the combination of its monophasic course, rapid clinical decline with the early occurrence of tetraparesis, the requirement of ventilation support and the concurrent absence of typical abnormal findings in MRI. Although TBE starts to be less frequent owing to the vaccination mainly in the developed countries, the neurologists and ICU specialits must be alert of this disease in all meningoencephalomyelitic patients with a severe clinical course - it means not only in subjects living in (as they are more frequenty vaccinated), but also in those travelling to the areas of risk (as most of the tourists do not undergo TBE vaccination before their journey). That is why the physicians from all over the world can encounter patients suffering from TBE, even in very serious clinical state.

\section{REFERENCES}

1. Hannoun C (1980). Les encephalities a tiques en Europe. Med. Trop. (Mars.) 40, 509-19.

2. Tomazic J, Poljak M, Popovic P, Maticic M, Beovic B, AvsicZupanc T, Lotric S, Jereb M, Pikelj F, Gale N (1997) Tick-borne encephalitis: possibly a fatal disease in its acute stage. PCR amplification of TBE RNA from postmortem brain tissue. Infection 25, 41-3.

3. Kaiser R (1999) The clinical and epidemiological profile of tick-borne encephalitis in southern Germany 1994-98: a prospective study of 656 patients. Brain 122, 2067-78.

4. Roggendorf M, Goldhofer E, Heinz FX, Epp C, Deinhardt F (1981) Frühsommer-Meningoenzephalitis in Süddeutschland. MMW Munch. Med. Wochenschr. 123, 1407-11.

5. Henigst W (1997) [Tick-borne encephalitis in southeastern Bavaria]. Med. Klin. 72, 1822-8.

6. Ackermann R, Rehse-Kupper B (1979) Die Zentraleuropäische Enzephalitis in der Bundesrepublik Deutschland. Fortschr. Neurol. Psychiatr. Grenzgeb. 47, 103-22.

7. Jezyna C, Zajac W, Ciesilski T, Pancewicz S (1984) Epidemiologische und klinische Untersuchungen von Kranken mit ZeckenEnzephalitis aus Nord-Ostpolen. Zentralbl. Bakteriol. Mikrobiol. Hyg. 178, 510-21.

8. Anic K, Soldi I, Peric L, Karner I, Barac B (1998) Tick-borne encephalitis in eastern Croatia. Scand. J. Infect. Dis. 30, 509-12.

9. Falisevac J, Beus I. Clinical manifestation of tick-borne encephalitis in Croatia. In: Kunz C, editor. Tick-borne encephalitis. Vienna: Facultas Verlag, 1981. p. 13-9.

10. Tiecks F, Pfister HW, Ray CG. Other Viral Infections. In: Hacke, W., editor. Neurocritical Care. Berlin: Springer-Verlag, 1994. p. $477-80$.

11. Günther G, Haglund M, Lindquist L, Forsgren M, Sköldenberg B (1997) Tick-borne encephalitis in Sweden in relation to aseptic meningo-encephalitis of other etiology: a prospective study of clinical course and outcome. J. Neurol. 244, 230-8.

12. Haglund M, Forsgren M, Lindh G, Lindquist L (1996) A 10-year follow up study of tick-borne encephalitis in the Stockholm area and a review of literature: need for vaccination strategy. Scand. J. Infect. Dis. 28, 217-24.

13. Holmgren B, Lindahl J, von Zeipel G, Swedmyr A (1959) Tick-borne meningoencephalomyelitis in Sweden. Acta Med. Scand. $164,507-22$.

14. Andersen LB, Larsen B, Korsager B (1994) Virusencephalitis after flatebid. Ugeskr. Laeger. 156, 5826-9.

15. Avšič-Županc T, Poljak M, Matičič M, et al. (1995) Laboratory acquired tick-borne meningoencephalitis: characterisation of virus strains. Clin. Diag. Virol. 4, 51-9.

16. Moritsch H (1962) Durch Arthropoden übertragene Virusinfektionen des Zentralnervensystems in Europa. Ergebn. Inn. Med. Kinderheilk. 17, 1-57.

17. Bodemann H, Hoppe-Seyler P, Blum H, Herkel L (1980) Schwere und ungunstige Verlaufsformen der Zeckenenzephalitis (FMSE) 1979 in Freiburg. Dtsch. Med. Wochenschr. 105, 921-4.

18. Gustafson R, Svenungsson B, Gardulf A, Stiermstedt G, Forsgren M (1990) Prevalence of tick-borne encephalitis and Lyme 
borreliosis in a defined Swedish population. Scand. J. Infect. Dis. 22, 297-306.

19. Duniewicz M (1976) Klinisches Bild der Zentraleuropaischen Zeckenenzephalitis. MMW Munch. Med. Wochenschr. 118, 1609-12.

20. Ackermann R, Kruger K, Roggendorf M, Rehse-Kupper B, Mortter M, Schneide M, Vukadinovic I (1986) Die Verbreitung der Frühsommer-Meningoenzephalitis in der Bundesrepublik Deutschland. Dtsch. Med. Wochenschr. 111, 927-33.

21. Köck T, Stünzner D, Freidl W, Pierer K (1992) Zur Klinik der Frühsommermeningoenzephalitis (FSME) in der Steiermark. Nervenarzt $63,205-8$

22. Kaiser R (1995) Tick-borne encephalitis in southern Germany [letter]. Lancet 345, 463.
23. Kunz C (1992) Tick-borne encephalitis in Europe. Acta Leidensia $60,1-14$.

24. Kaiser R (1996) Tick-borne encephalitis in southeastern Germany. Infection $24,398-9$.

25. Messner H. Pediatric problems of TBE. In: Kunz C, editor. Tick-borne encephalitis. Vienna: Facultas Verlag, 1981. p. 25-7.

26. Ziebart-Schroth A (1972) Frühsommer-Meningoenzephalitis (FMSE). Klinik und besondere Verlaufsformen. Wien. Klin. Wochenschr. 84, 788-81.

27. Goerre S, Kesselring J, Hartmann K, Kuhn M, Reinhart WH (1993) Neurologische Nebenwirkungen nach Impfung gegen die Frühsommer-Meningo-Enzephalitis. Fallbericht und Erfahrungen der Schweizerischen Arzneimittel-Nebenwirkungszentrale (SANZ). Schweiz. Med. Wochenschr. 123, 654-7. 